\title{
Incidence and clinical forms of tuberculosis in HIV infected adults: 2013 versus 2007
}

\author{
Olivia Burcoș ${ }^{1 *}$, Simona Erscoiu², Ionuț Cristian Popa ${ }^{1}$, Cristina Pătru1, Tatiana Stoicev ${ }^{1}$, Olimpia Nicolaescu', \\ Maria Nica², Andreea Todiran ${ }^{1}$, Grațiela Țârdei ${ }^{1}$, Emanoil Ceauşu ${ }^{2}$ \\ From The 7th Romanian National HIV/AIDS Congress and The 2nd Central European HIV Forum \\ Sibiu, Romania. 29-31 May 2014
}

Tuberculosis (TB), yet an endemic disease in Romania with a high prevalence compared to the average European incidence, had a slight descendent curve. But in the last 3 years we noticed a new phenomenon: an epidemic of tuberculosis among newly HIV infected intravenous drug users (IVDU). Objective: to determine the incidence, clinical and epidemiological characteristics of the new TB cases and TB reactivation in two different years, 2007 and 2013 (before and after HIV epidemic in IVDU) in our clinic of HIV infected adults.

We found a higher incidence of new infected TB cases or TB reactivation in 2013 (45 cases) versus 22 cases in 2007. The average age of patients was lower (33.6 years) in 2013 than in 2007 (35.6). Predominance of male patients was higher in 2013 (79\%) vs. $76 \%$ in 2007 . HIV transmission in 2013: 61\% IVDU, 35\% sexual transmission, $2 \%$ horizontal transmission cohort; in $200774 \%$ sexually transmitted infection, $14 \%$ horizontal infections. In 2013, $41 \%$ of HIV-TB coinfected patients were romani ethnics (81\% of them IVDU) versus 5\% in 2007.

The localization of TB infection was comparable in 2013/2007: disseminated TB 46\% vs. $51 \%$, pulmonary TB $51 \%$ vs. $50 \%$, peripheral adenopathy 1 case each year.

In 2007 we had $47 \%$ patients with sensibility to the 2 major first class drugs - hydrazine $(\mathrm{H})$ and rifampin $(\mathrm{R})$, resistance to $\mathrm{H}$ 6\%, to R 12\%, MDR 6\%. In 2013 we have 85\% patients HR-sensitive, 3\% H-resistant, 3\% R-resistant and $10 \%$ MDR.

The global mortality of the two groups of patients was higher in 2007 than in 2013 (32\% vs. 23\%). Deaths related to TB infection were higher in 2013 than in 2007 (89\% vs. $57 \%)$. Many cases of TB in IVDU HIV infected patients were severe: ( $58 \%$ disseminated TB). Mortality among

"Clinical Hospital of Infectious and Tropical Diseases "Dr. Victor Babeș", Bucharest, Romania

Full list of author information is available at the end of the article
HIV-TB coinfected IVDU was $50 \%$, versus $8 \%$ in nonIVDU patients.

TB had a high prevalence in HIV patients, in 2013 as in 2007, involving significant mortality and morbidity. A lot of newly HIV infected persons are still late and very late presenters. We are expecting that the epidemic of ethnobotanic drugs will raise the prevalence of TB. New techniques of TB antibiogram can reduce mortality.

\section{Authors' details}

"Clinical Hospital of Infectious and Tropical Diseases "Dr. Victor Babeş", Bucharest, Romania. ${ }^{2}$ Carol Davila University of Medicine and Pharmacy, Bucharest, Romania.

Published: 29 May 2014

doi:10.1186/1471-2334-14-S4-P23

Cite this article as: Burcos et al:: Incidence and clinical forms of tuberculosis in HIV infected adults: 2013 versus 2007. BMC Infectious Diseases 2014 14(Suppl 4):P23.

Submit your next manuscript to BioMed Central and take full advantage of:

- Convenient online submission

- Thorough peer review

- No space constraints or color figure charges

- Immediate publication on acceptance

- Inclusion in PubMed, CAS, Scopus and Google Scholar

- Research which is freely available for redistribution

Submit your manuscript at www.biomedcentral.com/submit
() Biomed Central 